\title{
commentary and analysis
}

\author{
- Landsat-7 Reveals More Than Just Surface Features in Remote Areas of the Globe \\ - Comments on "A Climatology of Derecho-Producing Mesoscale Convective Systems in the Central \\ and Eastern United States, 1986-95. Part I: Temporal and Spatial Distribution"
}

- Reply

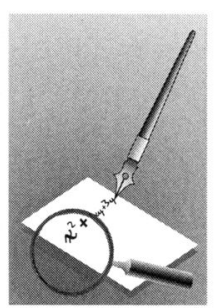

\section{Landsat-7 Reveals More Than Just Surface Features in Remote Areas of the Globe}

The Landsat-7 enhanced thematic mapper plus, ETM+ (Fig. 1), has been gathering information about the earth's surface since early June 1999. On 18 September 1999, while performing a routine quality check of Landsat-7 ETM+ images being processed at the U.S. Geological Survey's Earth Resources Observation Systems (EROS) Data Center in Sioux Falls, South Dakota, an unusual pattern within some clouds was found and passed to the Science Department at EROS. The science department identified the feature as the classic, but rarely observed, fluid flow pattern known as a Kármán vortex street.

The Landsat image (Fig. 2) was taken off the Chilean coast near the Juan Fernandez Islands (also known as the Robinson Crusoe Islands) on 15 September 1999 (Fig. 3). The rectangular-shaped island in Fig. 3 is Alejandro Selkirk Island $\left(33.75^{\circ} \mathrm{S}, 80.75^{\circ} \mathrm{W}\right)$. It is $6.44 \mathrm{~km}$ wide, $12.88 \mathrm{~km}$ long, at least $0.6 \mathrm{~km}$ above sea level throughout the island, and has a maximum peak of $1640 \mathrm{~m}$ above sea level. This area lies within the largest of four major regimes of marine stratocumulus clouds, which have a strong diurnal cycle with a nocturnal maximum of thickness and cloud fraction. They dominate the net cloud forcing, especially during summer months, and cause a net cooling of global surface temperature.

The island creates a system of vortices that stabilizes downwind of the object. The unsteadiness of the wind field, cross-island angle of the wind field, fluid characteristics, and topographical features of the island contribute to the alternating appearance of vortices. The vortices off the west (left) side of the island rotate clockwise, whereas those off its east (right) side rotate counterclockwise. Their centers are separated by some distance, $l$, along a given lane, and by a distance, $h$, along a perpendicular to each lane (Fig. 4). Von
Kármán found that the ratio, $h / l$, had to be 0.281 in order for the vortex arrangement to be stable within flow past a cylinder (Yuan 1967). The equivalent value for $h / l$ in Fig. 1 falls between 0.4 and 0.5 .

We have a stratified atmosphere in which turbulent air (Reynolds number between 80 and 200) flowing past the rectangular Alejandro Selkirk Island creates a system of vortices. The vortices actually form in the separated region of the laminar boundary layer airflow. Locating the point of boundary layer

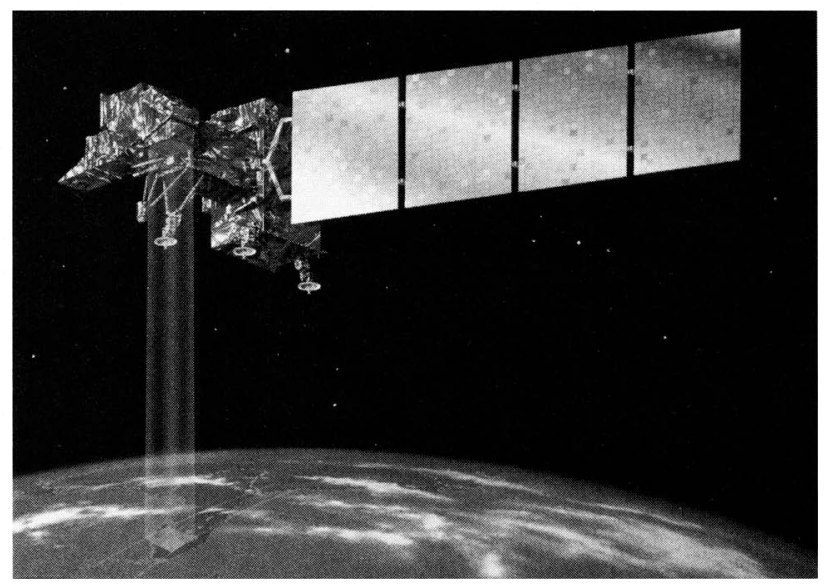

FIG. 1. Conceptualization of Landsat-7 and its ETM+ instrument in orbit over Florida. Landsat-7 is about $4.3 \mathrm{~m}$ long and $2.8 \mathrm{~m}$ in diameter. The ETM+ instrument is an eight-band multispectral scanning radiometer capable of providing highresolution imaging information of the earth's surface. Landsat7 views a 183-km-wide swath when in its sun-synchronous orbit at an altitude of $705 \mathrm{~km}$, a $98^{\circ}$ inclination, a descending equatorial crossing time of $1000 \mathrm{LT}$, and a 16-day repeat cycle. Each scene along its swath is $183 \mathrm{~km}$ wide by $170 \mathrm{~km}$ long and contains approximately $3.8 \mathrm{~GB}$ of data. Nominal ground sample distances, or pixel sizes, are $15 \mathrm{~m}$ in the panchromatic band $(0.5-$ $0.9 \mu \mathrm{m}) ; 30 \mathrm{~m}$ in the six visible $(0.45-0.52,0.53-0.61,0.63-$ $0.69 \mu \mathrm{m})$, near $(0.78-0.90 \mu \mathrm{m})$, and shortwave $(1.57-1.78$, $2.10-2.35 \mu \mathrm{m})$ infrared bands; and $60 \mathrm{~m}$ in the thermal infrared band $(10.5-12.5 \mu \mathrm{m})$. The bandwidths provided are halfamplitude bandwidths. (Courtesy of NASA and obtained through EROS Data Center, U. S. Geological Survey.) 


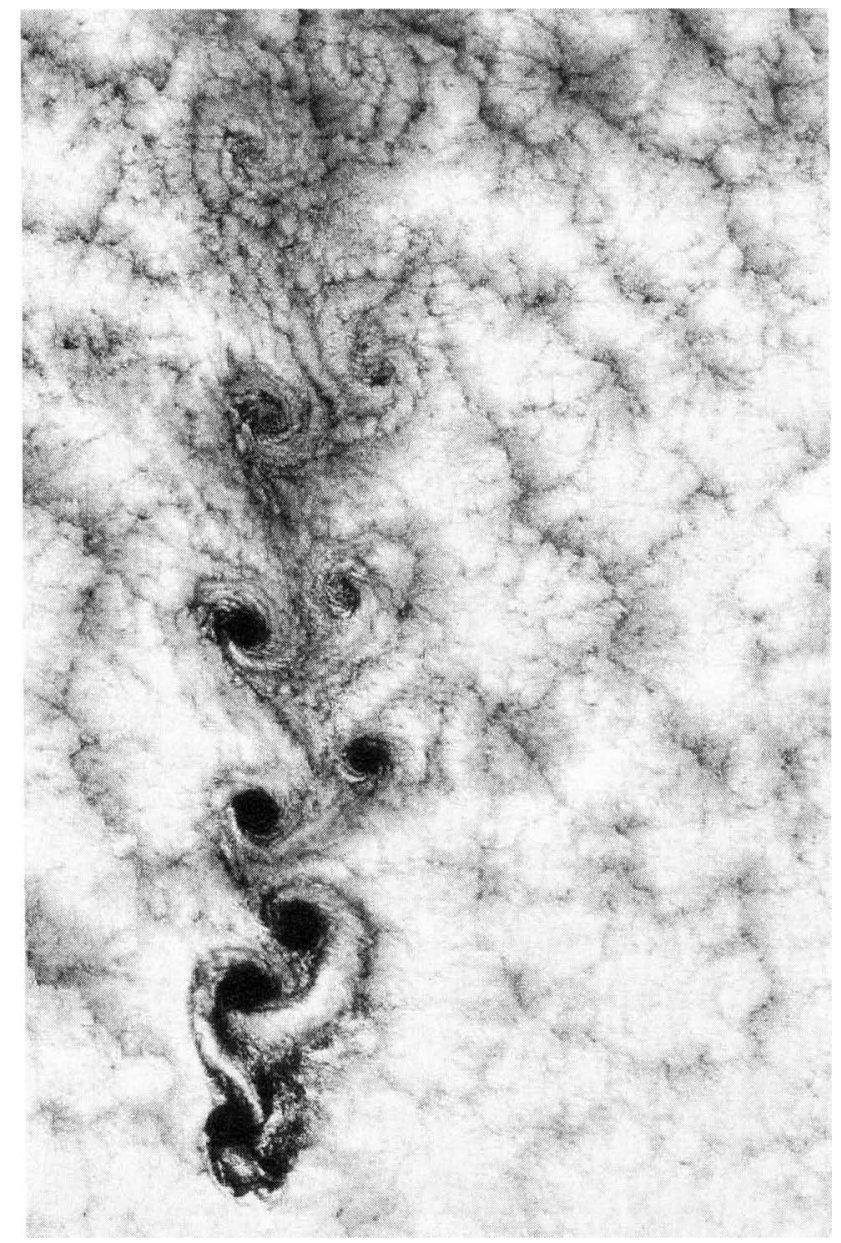

FIG. 2. The origin of the featured fluid flow appears to be Alejandro Selkirk Island of the Juan Fernandez Islands $\left(33.75^{\circ} \mathrm{S}\right.$, $80.75^{\circ} \mathrm{W}$ ), known as the Robinson Crusoe Islands. Alejandro Selkirk Island (i.e., the object), whose highest peak is approximately $1640 \mathrm{~m}$ above sea level, is approximately 6.44 $\mathrm{km}$ wide, $12.88 \mathrm{~km}$ long, and at least $0.6 \mathrm{~km}$ above sea level throughout the island. (Courtesy of the Satellite Systems Branch, U.S. Geological Survey, EROS Data Center, Sioux Falls, SD.)

separation requires knowledge of the pressure and free-stream velocity distributions in the vicinity of this island. The areas within the vortex centers are generally clear because the rotating motions induce a vertical wind component whose strength increases with the speed of the rotating air. The direction of the vertical air motions induced by vortices can be determined by using the left-hand rule since we are in the Southern Hemisphere. Thus, a counterclockwise rotation induces a subsiding motion, whereas a clockwise rotation induces a rising motion. The vortices with induced rising air motions appear cloud free because the latent heat released from the cloud droplets that initially form becomes concentrated in the
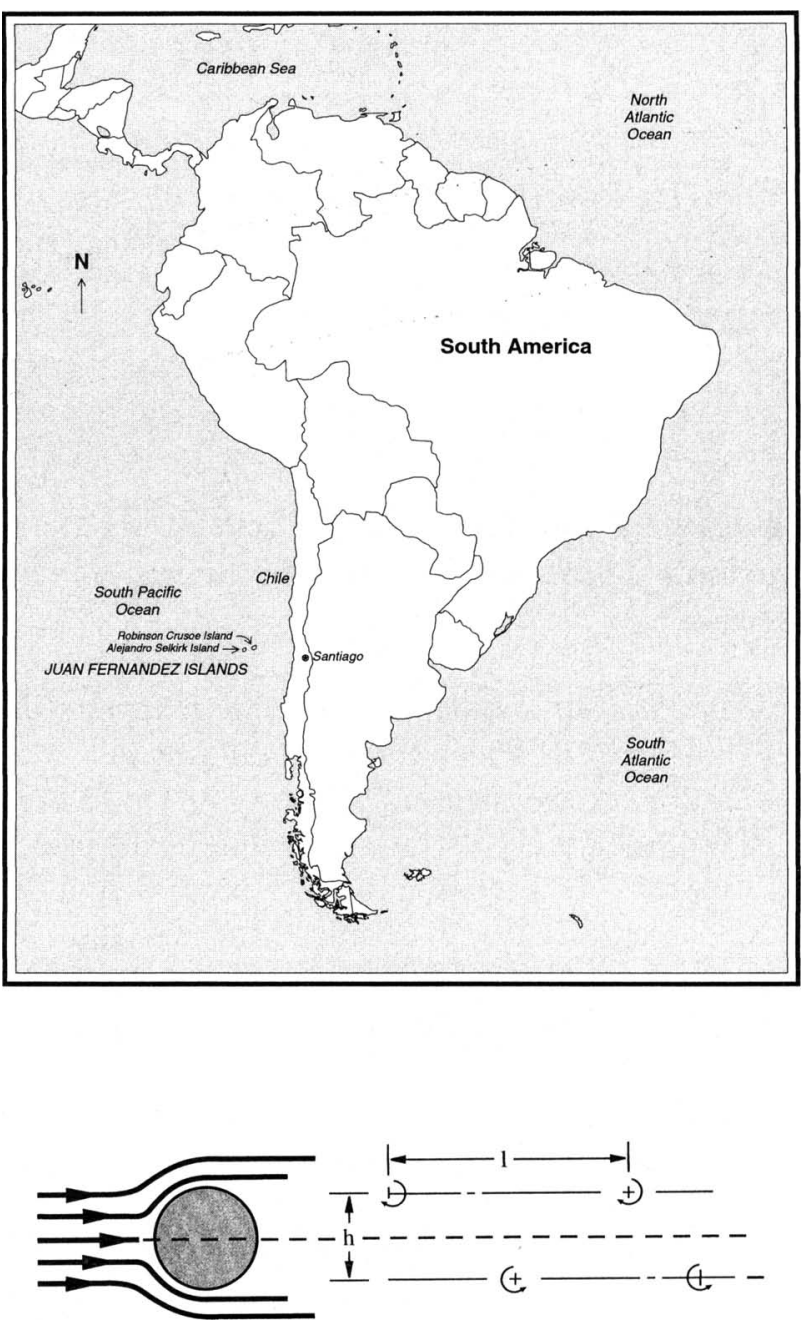

FIG. 4. A schematic showing the system of vortices known as the Kármán vortex street. Adapted from Yuan (1967).

centermost part of these vortices and is enough to evaporate the clouds. As the vortices propagate downstream, their rotational velocities weaken, causing the vorticity centers to fill.

There is a plan to further investigate the physics of the fluid within this image, and these results will be forthcoming. We also wish to note that Kármán vortex streets have been observed on meteorological satellite imagery, for example, around Socorro Island (eastern Pacific off Mexican coast) by R. Fett in the Naval Tactical Application Guide. Space shuttle astronauts have even observed Kármán vortex streets.

Acknowledgments. I would like to provide special thanks to the following for their particular contributions to this piece: Jon Christopherson for finding the image; Ron Hayes for locating the island characteristics; Jay Feuquay and the USGS for allowing us to use the Landsat-7 image; NASA/USGS press kit (April 1999); Ron Morfitt for reviewing parts of this manuscript; the 
two anonymous reviewers who provided constructive and inspirational reviews; and Professor John Lewis for encouraging this publication.

\section{References}

Yuan, S. W., 1967: Foundations of Fluid Mechanics. Prentice Hall, 608 pp.
T. P. DeFelice, D. J. Meyer, and G. Xian

Raytheon, SCIENCE DepartMENT

Science and Applications Branch, EROS Data Center

Sioux Falls, South Dakota

J. Christopherson

Raytheon, Satellite Systems Engineering and

Development Department

Satellite Systems Branch, EROS Data Center

Sioux Falls, South DaKota

R. CAHALAN

NASA/Goddard Space Flight Center

LABORATORY FOR ATMOSPHERES

GREENBELT, MaRYLAND
Comments on "A Climatology of DerechoProducing Mesoscale Convective Systems in the Central and Eastern United States, 1986-95. Part I: Temporal and Spatial Distribution"

In a 1987 paper, Johns and Hirt (1987, hereafter JH87) defined the derecho phenomenon in contemporary terms and systematically identified cases occurring during the months of May through August in the 4-yr period 1980-83. Although this work suggests a warm-season high-frequency axis exists from the upper Mississippi Valley into the mid-Atlantic states, it could not be considered a climatological distribution for warm-season derechos since only $4 \mathrm{yr}$ of data were included in the study. In the paper discussed here, Bentley and Mote (1998, hereafter BM98) have systematically screened data from all seasons for the $10-\mathrm{yr}$ period 1986-95 to develop a climatology of derechoproducing convective systems. They have found several features that add to our knowledge of derecho frequency distribution. Besides finding the highfrequency axis as had been suggested by JH87, they found an area of higher frequency across the central and southern plains, as well as a winter/spring highfrequency axis from eastern Texas into the Carolinas. They further noted that many of the warm-season cases in the central and southern plains appear to have strong southerly components of propagation resembling "southward bursts" as defined by Porter et al. (1955).

We agree with these general findings. However, we take issue with the distribution of frequency values, particularly those displayed for the warm-season cases (their Figs. 1b and 4). BM98's maximum frequency for derecho-producing mesoscale convective systems (MCSs) (hereafter identified as DMCSs) during the warm season resides in central-northeastern Oklahoma. Further, the BM98 results suggest that during the warm season a point in central-northeastern Oklahoma is 4-5 times more likely to experience a derecho than are most locations in the upper Mississippi Valley region. While higher frequencies might be expected in the central and southern plains region than what JH87's study suggested, the extreme frequency differences displayed in this study appear inconsistent based on operational experience.

BM98 have reasoned that the differences in warmseason frequency patterns between JH87's study and their own findings (Fig. 1) are the result of an anomalous midlevel flow pattern during the short period used for JH87's study. We believe that this effect may explain some of the differences, but not to the extreme displayed in Fig. 1. The month of July has the highest frequency of derecho occurrence nationwide in BM98's study and is close to having the highest frequency in JH87's study. However, the average $500-\mathrm{mb}$ flow pattern for July (both for a $20-\mathrm{yr}$ period in general and for the anomalous year of 1980; their Figs. $2 \mathrm{~b}$ and $2 \mathrm{~d}$, respectively) shows a ridge axis extending generally east-west across the southern plains. This pattern suggests that midlevel flow strong enough to maintain vigorous, rapidly moving, and long-lived bow echoes over Oklahoma would be very infrequent during July. Therefore, BM98's pronounced warmseason frequency maximum over Oklahoma is difficult to explain given typical warm-season flow patterns.

We believe there are several nonmeteorological factors that are likely affecting BM98's results for 

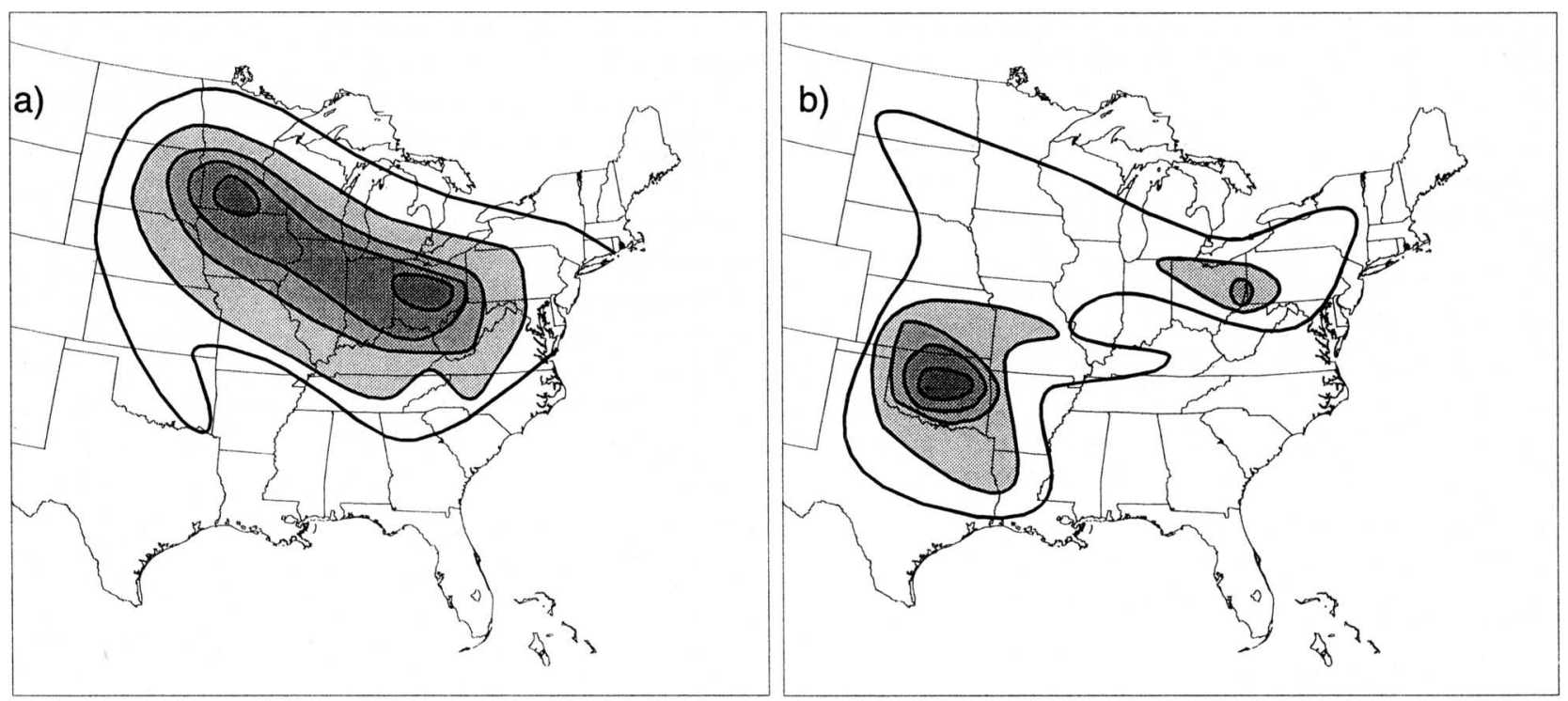

\section{\begin{tabular}{l|l|l|l|l|l|l|l|l}
$3-5$ & $6-8$ & $9-11$ & $12-$ & 15 \\
\hline
\end{tabular}}

FIG. 1. Total number of derechos occurring during the warm season for (a) 1980-83 (from JH87) and (b) 1986-95 (from BM98). (After BM98.)

derecho frequency distribution values. These factors involve 1) use of methodology and criteria to define derechos that are different from those used by JH87, and 2) changes in the nature and quality of storm reports between the period studied by JH87 (1980-83) and that studied by BM98 (1986-95).

BM98's methodology and criteria for identifying derechos and determining the area affected differs with that of JH87 in the following ways. In contrast to JH87, BM98 did not consult National Weather Service radar summary charts to determine the presence of bowed line segments with progressive wind reports. Rather, they increased the density requirements of wind reports in both space and time and assumed the presence and areal extent of a bow echo complex and derecho, based on the progressive reports only. Further, BM98 eliminated the requirement for F1 or greater intensity damage and/or maximum wind gusts of $33 \mathrm{~m} \mathrm{~s}^{-1}(65 \mathrm{kt})$ or greater (see criterion c on p. 33 of JH87). We believe that these changes in criteria have allowed slower-moving MCSs or clusters of individual thunderstorm cells in relatively weak vertical shear situations to be included in the BM98 dataset. Such convective systems can exhibit progressive wind events, but these events tend to be associated with isolated downbursts scattered along relatively slowmoving gust fronts or along the tracks of individual cells. [Note that JH87 found that over $90 \%$ of the pro- gressive derechos in their dataset moved at a speed of $18 \mathrm{~m} \mathrm{~s}^{-1}(35 \mathrm{kt})$ or greater, which implies a similar motion for the associated bow echoes.] Further, wind events associated with such "weak vertical shear" systems are less likely to be as intense (have gusts $33 \mathrm{~m} \mathrm{~s}^{-1}$ or greater) as those associated with rapidly moving bow echoes. Elimination of the maximum gust requirement makes it more likely these types of systems are included in the BM98 database.

BM98's use of "density of reports" criteria that are tighter (denser in both time and areal coverage) than that used by JH87 likely results in BM98's dataset being more sensitive to differences in population density. Generally, population densities in the northern Plains are lower than in the southern plains. For example, Oklahoma and North Dakota have approximately the same land area (North Dakota is slightly larger). However, in the 1990 census the population of Oklahoma (over 3 million people) was about 5 times greater than that of North Dakota (less than 650000 people) (U.S. Census Bureau 1999). The lower population density in the northern plains may contribute to the relatively low frequency values for BM98's summer cases in that region (Fig. 1b).

The nature of the convective wind report database (Schaefer and Edwards 1999) has changed in recent years and so have the biases. In the period used for JH87's study (1980-83), warning verification in the 
National Weather Service (NWS) was just beginning to receive emphasis. Severe wind events were generally underreported. In more recent years, including much of the period used for BM98's study (1986-95), honing of the NWS's warning verification system (beginning in the 1980s) and installation of the WSR-88D Doppler radar network (beginning in the early 1990s) have resulted in an exponential increase in reported severe wind events (e.g., Weiss and Vescio 1998). Comparison of all severe convective wind reports occurring during the warm season (MayAugust) for the 10-yr period of BM98's study with the corresponding dataset for the previous $10 \mathrm{yr}$ (1976-85) illustrates the large increase in reports in most areas east of the Rocky Mountains (Fig. 2). Further, much of the increase involves marginally severe reports (Weiss and Vescio 1998), many of which are subjectively determined [e.g., winds estimated at $60 \mathrm{mph}$, but causing no damage; see also section II in NOAA (1998)]. It is probably not coincidental that the annual number of derechos in BM98's dataset increases dramatically in 1994 and 1995 (see their Fig. 21). This coincides with the rapid expansion of the National Weather Service's WSR-88D operational radar network and a corresponding acceleration in the annual increase in severe weather reports nationwide (see Fig. 1 in Weiss and Vescio 1998).

Despite the rapid increase in the number of wind reports generally in recent years, significant regional variations in the change in reports exist, and these variations likely reflect both differences in the aggressiveness of local NWS verification programs as well as changes in population density. For example, from the period 1976-85 to the period 1986-95, the increase in reports over portions of the southern plains region (Fig. 3) appears to be considerably greater than the increase from western Lake Michi- gan into Minnesota (Fig. 4). The former area corresponds with BM98's greatest warm-season high-frequency maximum (Fig. 1b), while the latter area corresponds with the western portions of JH87's warm season derecho high-frequency axis (Fig. 1a). Much of the extreme increase in reports $(300 \%-500 \%)$ over portions of the southern plains region is likely related to very aggressive verification programs instituted by several individual NWS offices in the region in recent years. However, close inspection of Fig. 4 also reveals
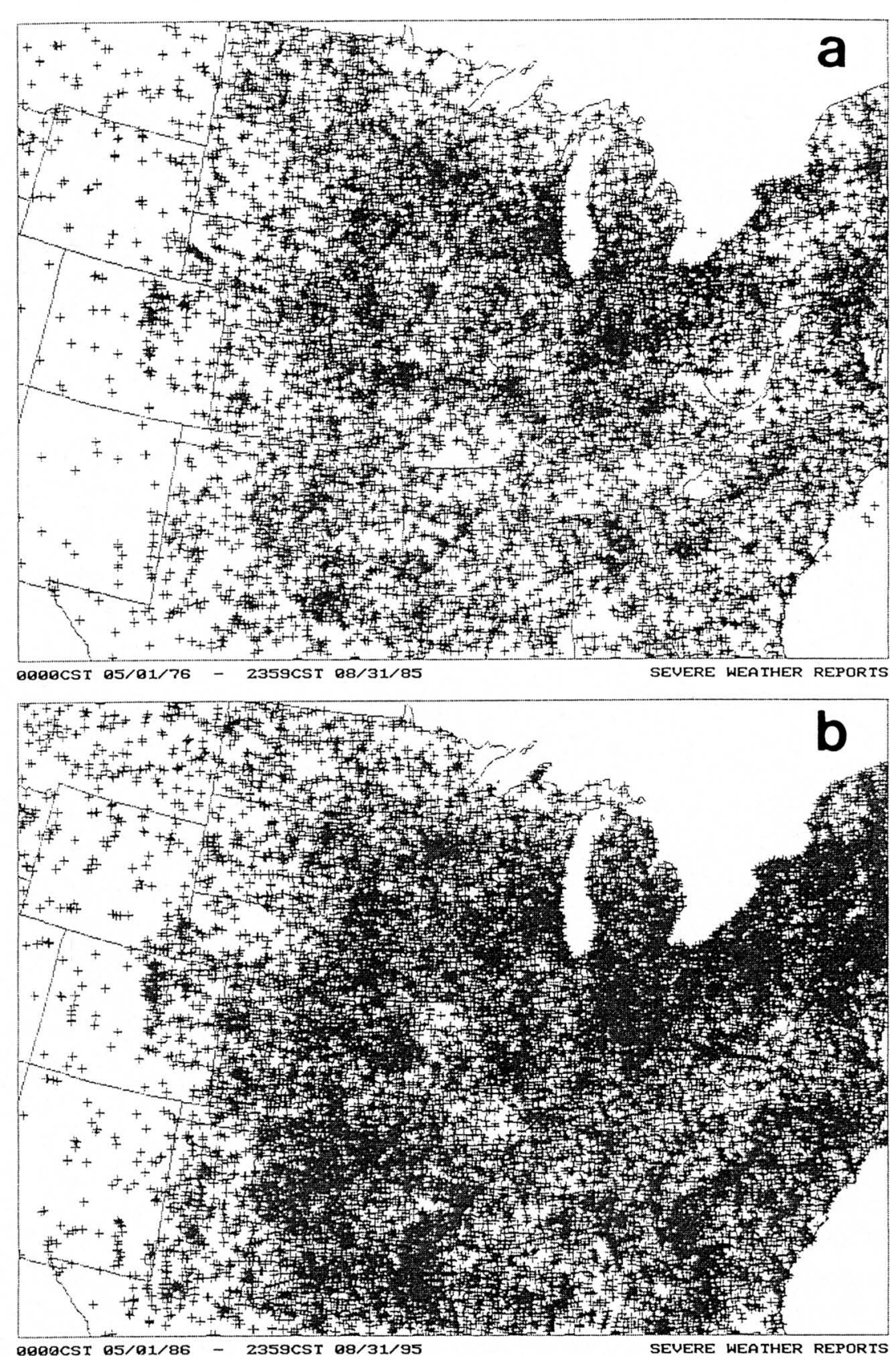

FIG. 2. Total number of severe convective wind reports occurring during the warm season (May-Aug) for the years (a) 1976-85 and (b) 1986-95. 

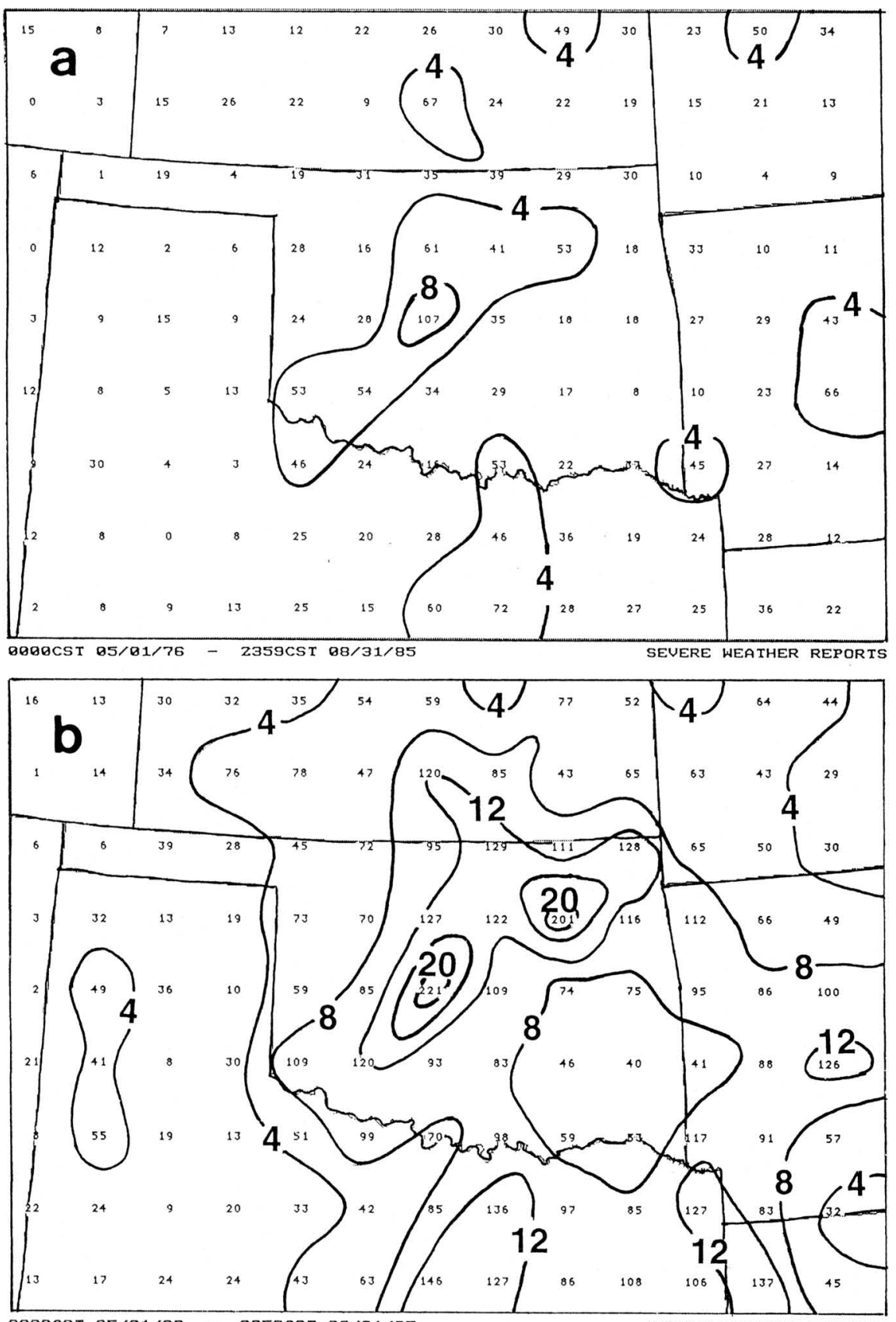

FIG. 3. Total number of severe convective wind reports occurring in $100 \mathrm{~km}$ by $100 \mathrm{~km}$ squares in portions of the southern plains during the warm season (May-Aug) for the years (a) 1976-85 and (b) 1986-95. Isopleth labels are in tens of reports.

BM98's tighter report density requirements and elimination of the $33 \mathrm{~m} \mathrm{~s}^{-1}$ wind criterion, along with their more recent period of study, likely result in their maxima in frequency being biased toward areas where very aggressive verification programs are in place. Further, their relatively low frequencies in the northern plains appear to be affected by the recent loss in population in parts of the region. We believe that these factors are primary contributors to the differences between BM98's warmseason frequency maxima and those of JH87.

There is another aspect of BM98's methodology that differs from that of JH87 and may result in an overestimation of derecho occurrence in situations with "moderate to strong wind shear." As a final check in identifying cases, JH87 examined NWS radar summary charts to identify the bow echo stage of DMCSs. Although not explicitly mentioned in the text of JH87, only wind and/or wind damage reports associated with the bow echo stage of DMCSs were included in the JH87 database. In contrast, BM98's methodology includes wind damage reports from non-bow echo stages of DMCSs. This affects the major axis length criterion for identifying derechos as well as the areal coverage for frequency tabulations. For example, the isolated high-precipitation supercell

that the number of wind reports over portions of North Dakota and northwestern Minnesota have actually $d e$ creased with time! This decrease may be linked to a corresponding decrease in population density. For example, while most of the nation, including Oklahoma, recorded population increases between 1980 and 1990, North Dakota lost $2 \%$ of its inhabitants (U.S. Census Bureau 1999). that passed through Lahoma, Oklahoma, on 17 August 1994 qualifies as one of BM98's warm-season derecho cases (see their Fig. 6). This situation did involve large-scale bow echoes during its latter stages over southwestern Oklahoma and north-central Texas. However, wind reports associated with the portion of the DMCS that was primarily supercellular in nature from southern Kansas into central Oklahoma (see 
Conway et al. 1996) would not have been included for derecho computations using JH87 methodology. Thus, the 17 August 1994 case either would not have qualified as a derecho because of failing the major axis length criterion, or if it did qualify, the areal coverage would be less than is the case using BM98 methodology. Such "isolated supercell to bow echo" transitions appear to be most frequent in the Great Plains and would be detected most frequently by BM98's criteria in portions of the central and southern plains where the population density is greatest. Examination of the reports associated with BM98's central and southern plains derecho cases suggests there are likely several other isolated supercell to bow echo transition events in the dataset, in addition to the 17 August 1994 case. Such cases contribute to BM98's warm-season frequency maximum for derechos over the southern plains.

As was mentioned in the first paragraph of this document, the 4-yr time period used by JH87 was too short for determining a climatology of derecho occurrence. This question also arises as to whether the 10-yr period used by BM98 is sufficient to determine a climatology. Certainly, anomalous warmseason precipitation regimes in the midlatitudes can span sev-
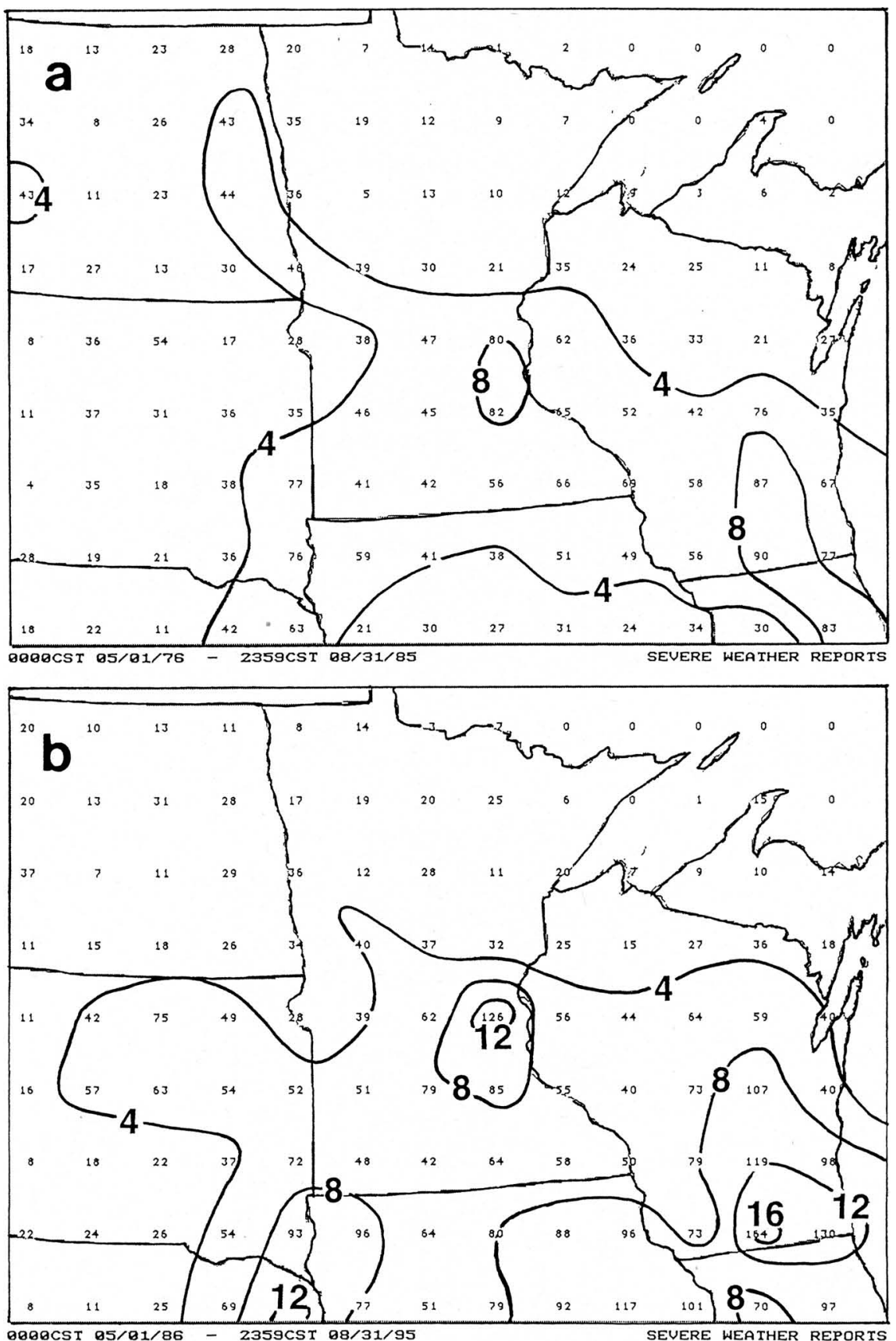

FIG. 4. As in Fig. 3 except for portions of the northern plains and upper Mississippi Valley. eral years (e.g., the dust bowl years in the 1930s), and these regimes are associated with anomalous jet stream patterns, which also affect the areas favorable for bow echo development. During the period of BM98's study, the "Great Flood" year of 1993 was typified by an anomalous southward shift in the jet stream during the summer months. Were there other "anomalous southward shift" years in the BM98 dataset? It is beyond the scope of this note to determine if there is an "anomalous pattern"

bias to the BM98 dataset. If, however, such a bias exists, it would likely have less of a negative effect on the derecho climatology than do the effects of BM98's methodology and criteria used to identify derechos, and the changes in the nature and quality of storm report data described earlier.

In summary, we believe BM98's climatology of derecho-producing mesoscale convective systems does represent the primary axes of derecho activity 
during the annual severe weather cycle. However, we also believe that their changes in methodology and criteria have distorted the actual frequency values and the geographical locations of frequency maxima. Essentially, BM98's warm-season frequency values in the southern plains appear to be too high, while their values from the northern plains into the central Great Lakes-lower Ohio Valley region appear to be too low. We believe that any future attempts to address derecho climatology should include identification of a long-lived bow echo structure as one of the criteria. ${ }^{1}$ Also, because of the proliferation of marginally severe wind reports in recent years, we believe the maximum wind gust requirement of $33 \mathrm{~m} \mathrm{~s}^{-1}$ (65 kt) or greater (or F1 or greater intensity damage) used by JH87 should be retained. Finally, knowledge of the biases in severe weather reporting (including the changes in biases with time) is necessary when designing a severe weather climatology and in interpreting the results.

\section{References}

Bentley, M. L., and T. L. Mote, 1998: A climatology of derechoproducing mesoscale convective systems in the central and Eastern United States, 1986-95. Part I: Temporal and spatial distribution. Bull. Amer. Meteor. Soc., 79, 2527-2540.

${ }^{1}$ Note that once a multicellular bowed convective structure has developed, it may contain embedded mesocyclones (supercells) that can contribute to the severe derecho outflow winds [e.g., the case of 25 May 1976 described by Moller et al. (1990)].
Conway, J. W., H. E. Brooks, and K. D. Hondl, 1996: The 17 August 1994 Lahoma, OK supercell: Issues of tornadogenesis and bow echo formation. Preprints, 18th Conf. on Severe Local Storms, San Francisco, CA, Amer. Meteor. Soc., 52-56.

Johns, R. H., and W. D. Hirt, 1987: Derechos: Widespread convectively induced windstorms. Wea. Forecasting, 2, 32-49.

Moller, A. R., C. A. Doswell III, and R. Przybylinski, 1990: Highprecipitation supercells: A conceptual model and documentation. Preprints, 16th Conf. on Severe Local Storms, Kananaskis Park, AB, Canada, Amer. Meteor. Soc., 52-57.

NOAA, 1998: NWS's verification system for severe and hazardous weather forecasting needs modernization. Inspection Rep. IPE-9255/January 1998, Office of the Inspector General, Washington, DC, 73 pp. [Available online at http:// www.oig.doc.gov/reports/1998-3, as file "1998-309255.01.pdf'.]

Porter, J. M., L. L. Means, J. E. Hovde, and W. B. Chappell, 1955: A synoptic study of the formation of squall lines in the north central United States. Bull. Amer. Meteor. Soc., 36, 390-396.

Schaefer, J. T., and R. Edwards, 1999: The SPC tornado/severe thunderstorm database. Preprints, 11th Conf. on Applied Climatology, Dallas, TX, Amer. Meteor. Soc., 215-220.

U.S. Census Bureau, cited 1999: Historical annual time series of state population estimates and demographic components of change...1900 to 1990. [Available online at www.census.gov/ population/www/estimates/st_stts.html.]

Weiss, S. J., and M. D. Vescio, 1998: Severe local storm climatology 1955-1996: Analysis of reporting trends and implications for NWS operations. Preprints, 19th Conf. on Severe Local Storms, Minneapolis, MN, Amer. Meteor. Soc., 536539.

Robert H. Johns AND JefFry S. Evans NOAA/NWS Storm PRediction CEnTER Norman, OKLAHOMA

\section{Reply}

We welcome the opportunity provided by the comments of Johns and Evans (2000, hereafter JE00) toward a climatology of derecho-producing mesoscale convective systems (DMCSs). JE00 raise important questions regarding methodology developed to identify DMCSs in previous work (Bentley and Mote 1998, hereafter BM98; Johns and Hirt 1987, hereafter JH87).

As we understand their comments, JE00 are particularly concerned with derecho frequency distribution values used for producing Figs. 1 b and 4 from BM98. They believe that the warm-season frequency in the southern plains is too high, while the frequency from the northern plains into the central Great LakesOhio Valley region is too low. They believe changes in methodology from JH87 to BM98 and stormreporting criteria have produced these discrepancies.

One possible explanation for the discrepancy in warm-season DMCS frequency between BM98 and JH87 is identified by comparing the $500-\mathrm{hPa}$ height patterns exhibited during June and July 1980 (24\% of DMCSs identified by JH87 occurred during these months) to a $27-\mathrm{yr}$ average of $500-\mathrm{hPa}$ heights (Figs. 1a-d). JE00 and BM98 suggest anomalous ridging during the JH87 study may explain some of the discrepancy in the frequency distributions between 


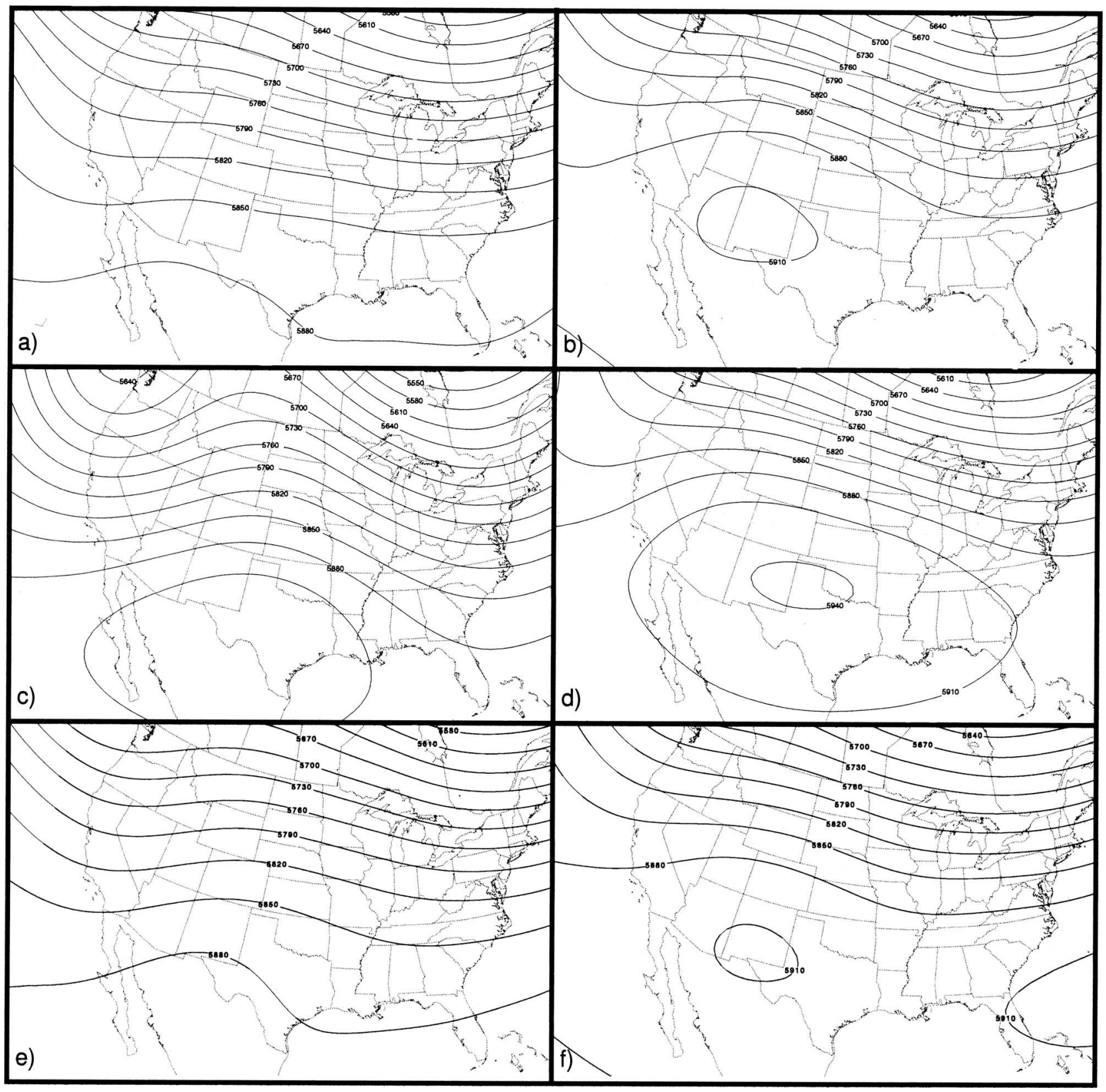

FIG.1. (A) Average 500-hPa height contours for Jun 1963-89. (b) Average 500-hPa height contours for Jul 1963-89. (c) 500-hPa height contours for Jun 1980 when seven derechos were identified by JH87. (d) 500-hPa height contours for Jul 1980 when 10 derechos were identified by JH87. (e) 500-hPa height contours for Jun 1986-95. (F) 500-hPa height contours for Jul 1986-95. [From Bentley (1999).]

BM98 and JH87. As shown in Fig. 1, and substantiated by Fig. 2 of JH87, conditions leading to DMCSs were more favorable in the northern plains-Great Lakes-Ohio Valley region during June and July 1980. Additionally, JE00 suggest the average $500-\mathrm{hPa}$ height pattern in July also would be unfavorable for DMCS occurrence in the southern plains. We agree and, in further examination of events in BM98 that moved through Oklahoma, found that only five warmseason DMCSs developed later than 19 June (Figs. 6, 7,
11, and 13). Eleven of the DMCSs affecting Oklahoma, documented in BM98, formed in May or early June.

JE00 also question whether a 10 -yr period used in BM98 is adequate to create a climatology of DMCSs. The authors compared June and July 500-hPa heights, months of high DMCS activity during the BM98 period, to the 1963-89 average 500-hPa heights (Figs. 1a,b,e,f). As shown, utilization of the 10-yr time period is representative of longer-term $500-\mathrm{hPa}$ height patterns. 
Methodological concerns raised by JE00 primarily concern the increase in density requirements from JH87 to BM98 between successive wind reports, eliminating the requirement for maximum wind gusts of $33 \mathrm{~m} \mathrm{~s}^{-1}$, and not determining the radar signature of the DMCS. In order to identify derechos without consulting National Weather Service radar summaries, BM98 established that no more than $2^{\circ}$ of latitude or longitude can separate successive wind reports. At $46^{\circ} \mathrm{N}, 100^{\circ} \mathrm{W}$ (i.e., northern plains) this spatial criterion allows no less than $155 \mathrm{~km}$ between successive wind reports. The authors believe that this requirement identifies DMCSs by assuring a progressive windstorm. BM98 also tightened the temporal restriction between successive wind reports. However, we also wanted to assure that the majority of derechos would be documented. The BM98 temporal criterion of no more than $2 \mathrm{~h}$ elapsing between wind reports draws upon and extends the 70-min periodicity between downburst clusters reported by Fujita and Wakimoto (1981). BM98 chose the smallest hourly interval possible that is greater than $70 \mathrm{~min}$. JE00 bring up a number of interesting points regarding changes in population density and increases in severe weather reports. It is uncertain whether the spatial and temporal criteria would be sensitive to these shifts. It should be noted, however, that the temporal and spatial criteria used in BM98 is nearly identical to that used to identify derecho-producing long-lived bow echo events by Evans (1998). Events were identified by a near-continuous damage path with no more than a 2-h or 100-mi $(161 \mathrm{~km})$ gap between successive concentrations of severe wind reports (Evans 1998). It should also be noted that the BM98 criteria identified 17 DMCSs in the northern plains/ Great Lakes-lower Ohio Valley corridor, making it the most active corridor of the climatology (BM98, Fig. 5).

JE00 also point out that the annual number of derechos in BM98's dataset and severe weather reports nationwide increased dramatically in 1994 and 1995. An increase in severe convective wind reports does not necessarily mean an increase in derechos, since severe convective wind swaths must show temporal and spatial continuity and progression. A favorable synoptic pattern in 1995 assisted in producing the increase in DMCSs (Bentley 1999; Bosart et al. 1998; BM98). Severe wind reports have been increasing exponentially since 1984 (Weiss and Vescio 1998); however, the annual frequency of derechos in BM98 remained virtually unchanged until 1994.

The authors believe an important factor affecting the frequency distribution in Figs. $1 \mathrm{~b}$ and 4 from
BM98 occurs due to the clustering of derecho events within each corridor. There is much less overlap between DMCS tracks in the summer season northern tier corridor than in the summer season southeastward moving central and southern Great Plains corridor (BM98, Figs. 5 and 6). Although fewer events moved through Oklahoma (15 DMCSs) than through the northern tier states (17 DMCSs) during the warm season (May-August), the tight grouping of DMCS tracks produced a significant maximum in Oklahoma when contouring the gridded frequency data (BM98, Fig. 16). A greater discrepancy between the number of DMCSs in each corridor exists in the summer months (June-August). Eleven events passed through Oklahoma during the summer, while 17 DMCSs occurred through the northern tier states (BM98, Figs. 5, 6,7 , and 8). Once again, the overlapping of derecho tracks produced a frequency maximum in Oklahoma (BM98, Fig. 4). The figures in BM98 document the primary DMCS corridors and illustrate the corresponding track of every derecho event (BM98, Figs. 5-8, 1115,17 , and 18). These figures illustrate the spatial distribution of DMCSs in some respect better than the frequency contours.

JH87 also employed the requirement of at least three wind reports of either F1 damage or wind gusts greater than $33 \mathrm{~m} \mathrm{~s}^{-1}$ separated by at least $64 \mathrm{~km}$. The authors chose not to use this criterion because it does not appear in JH87's definition of a derecho and due to uncertainties in wind speed estimates from the Storm Prediction Center's (SPC's) severe convective wind gust database. JH87 define the term derecho to include any family of downburst clusters produced by an extratropical MCS. More specifically, a downburst cluster is defined as an overall area of wind damage consisting of two or more strong downdrafts that induce an outburst of damaging winds (Fujita and Wakimoto 1981). No references are made to specific wind speed criteria for downburst clusters other than "damaging," which implies a wind speed greater than $25 \mathrm{~m} \mathrm{~s}^{-1}$. Additionally, the SPC's severe convective wind gust database appears to underreport actual wind speed estimates for severe convective wind gusts. JH87's $33 \mathrm{~m} \mathrm{~s}^{-1}$ criterion could be too conservative to identify some derecho events. For example, only four wind gusts of $33 \mathrm{~m} \mathrm{~s}^{-1}$ or greater are listed for the severe Adirondack derecho of 15 July 1995, which damaged nearly a million acres of forest and resulted in at least five fatalities (Bentley 1995). We agree, however, with JE00 that this change in criteria would alter the derecho frequencies found in BM98. 
Another modification to the criteria used to identify derechos that also would produce somewhat different results was revealed in JE00. The JH87 study only utilized wind reports associated with the bow echo stage of MCSs. This was not mentioned in JH87 and would certainly affect derecho identification given the major axis length criterion and subsequent frequency tabulations. BM98 did not employ this technique or assume the presence and areal extent of a bow echo complex (JE00). The radar signature of the parent MCS is not a defining factor of the derecho. In fact, several cases of high-precipitation supercells that produced extreme winds over an extended distance have been identified as capable of producing derechos (Cummine et al. 1992; Smith 1993; Brooks and Doswell 1993). Revisiting the currently accepted definition, a derecho is a convective windstorm produced by an extratropical MCS regardless of radar signature or echo morphology. It is of the authors' opinion that a derecho is not defined by its parent MCS, much like a tornado is not defined by its associated thunderstorm.

In closing, the authors would like to emphasize that, overall, the findings of BM98 substantiated results obtained from JH87. There is more agreement than appears from just examining the frequency contours. Both investigations found that the primary warm-season derecho corridor, in terms of the number of events, occurred in the northern plains-Great Lakes-lower Ohio Valley. Discrepancies in the BM98 climatology and the JH87 study are primarily related to anomalous upper-air conditions during the JH87 study period; differences in the criteria used to identify DMCSs; interpretation of the contemporary definition of a derecho; and most importantly, the overlapping of events within activity corridors.

\section{References}

Bentley, M. L., 1995: Synoptic conditions favorable for the formation of the 15 July 1995 southeastern Canada-northeastern U.S. derecho event. Natl. Wea. Dig., 21 (2), 31-38.

- 1999: A climatology of derecho producing mesoscale convective systems in the eastern United States, 1986-1995. Ph.D. dissertation, University of Georgia, $136 \mathrm{pp}$. [Available from University of Georgia Libraries, Athens, GA 30602.]
— mesoscale convective systems in the central and eastern United States, 1986-95. Part I: Temporal and spatial distribution. Bull. Amer. Meteor. Soc., 79, 2527-2540.

Bosart, L. F., W. E. Bracken, and A. Seimon, 1998: Large-scale conditions associated with the northwesterly flow intense derecho events of 14-15 July 1995 in the northeastern United States. Preprints, 19th Conf. on Severe Local Storms, Minneapolis, MN, Amer. Meteor. Soc., 503-506.

Brooks, H. E., and C. A. Dowell III, 1993: Extreme winds in high precipitation supercells. Preprints, 17th Conf. on Severe Local Storms, St. Louis, MO, Amer. Meteor. Soc., 173-177.

Cummine, J., P. McCarthy, and M. Leduc, 1992: Blowdown over northwestern Ontario. A derecho event-18 July 1991. Preprints, 4th Workshop on Operational Meteorology, Whistler, BC, Canada, Atmospheric Environment Service and Canadian Meteorological and Oceanographic Society, 311-317.

Evans, J. S., 1998: An examination of observed shear profiles associated with long-lived bow echoes. Preprints, 19th Conf. on Severe Local Storms, Minneapolis, MN, Amer. Meteor. Soc., 30-33.

Fujita, T. T., and R. M. Wakimoto, 1981: Five scales of airflow associated with a series of downbursts on 16 July 1980. Mon. Wea. Rev., 109, 1438-1456.

Johns, R. H., and W. D. Hirt, 1987: Derechos: Widespread convectively induced windstorms. Wea. Forecasting, 2, 32-49.

— derecho-producing mesoscale convective systems in the central and eastern United States, 1986-95. Part I: Temporal and spatial distribution." Bull. Amer. Meteor. Soc., 81, 10491054.

Smith, B. E., 1993: The Concordia, Kansas downburst of 8 July 1992: A case study of an unusually long-lived windstorm. Preprints, 17th Conf. on Severe Local Storms, St. Louis, MO, Amer. Meteor. Soc., 588-592.

Weiss, S. J., and M. D. Vescio, 1998: Severe local storm climatology 1955-1996: Analysis of reporting trends and implications for NWS operations. Preprints, 19th Conf. on Severe Local Storms, Minneapolis, MN, Amer. Meteor. Soc., 536-539.

\author{
Dr. Mace L. Bentley \\ Kentucky Climate Center \\ Department of Geography and Geology \\ WESTERN KENTUCKY UNIVERSITY \\ Bowling Green, Kentucky \\ Dr. Thomas L. Mote \\ Climatology Research Laboratory \\ DEPARTMENT OF GEOGRAPHY \\ UNIVERSITY OF GEORGIA \\ Athens, Georgia
}




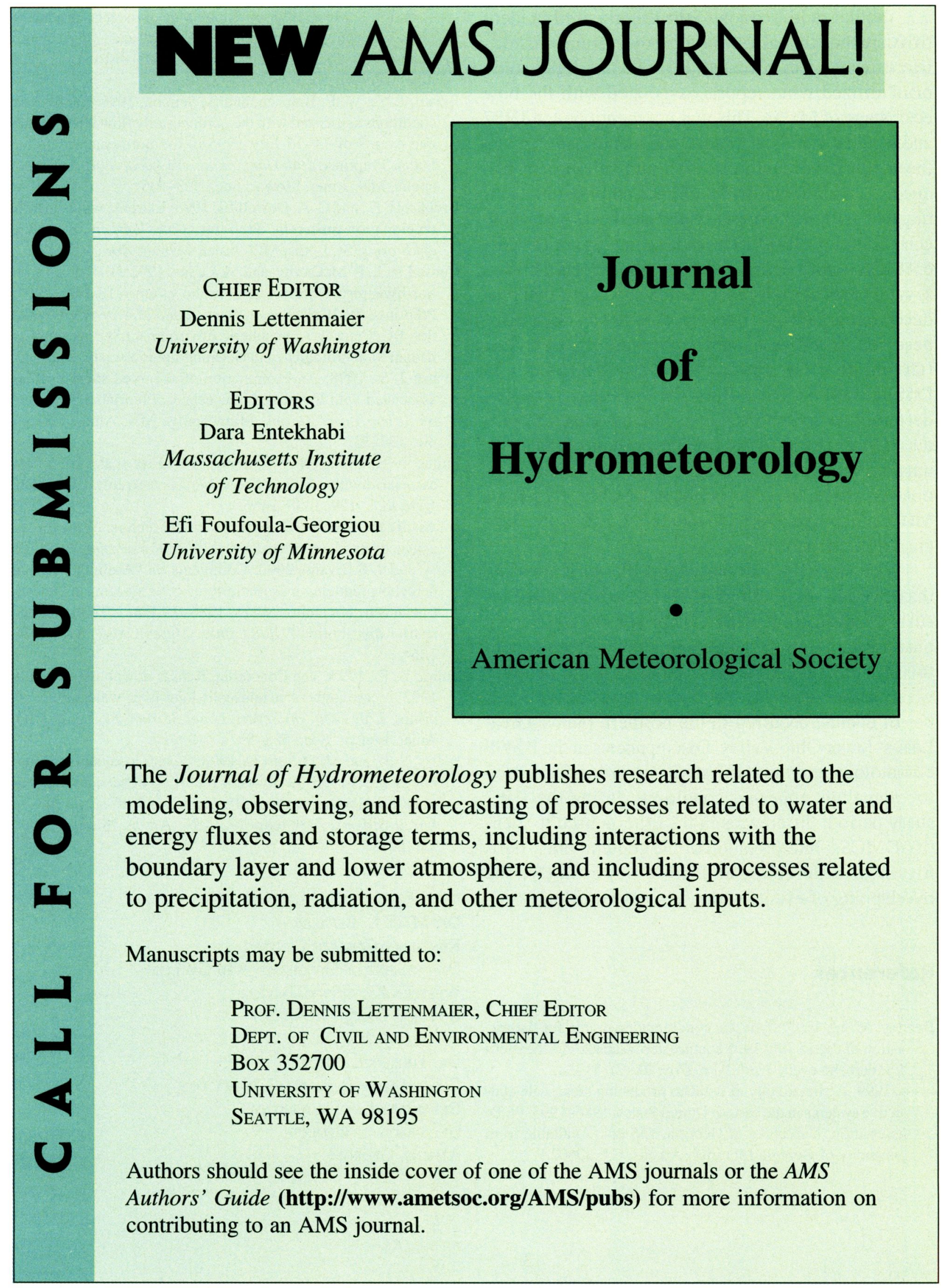

